\title{
ANÁLISE DOS EFEITOS DE UM EVENTO EXTREMO DE CHUVA SOBRE O ESCOAMENTO SUPERFICIAL EM UMA PEQUENA BACIA HIDROGRÁFICA RURAL AMAZÔNICA
}

\author{
RODRIGUES, Rodrigo Silvano Silva - r2rodrigo@gmail.com \\ Universidade Federal do Pará / UFPA
}
SILVA, Maria de Nazaré Alves da - nazare_alves@hotmail.com Universidade Federal do Pará / UFPA
FERREIRA FILHO, David Figueiredo - davydferreira@gmail.com Universidade Federal do Pará / UFPA
BEZERRA, Paulo Eduardo Silva - pauloeduardoea@gmail.com Universidade Federal do Pará / UFPA
FIGUEIREDO, Nélio Moura de - neliomfigueiredo@outlook.com Universidade Federal do Pará / UFPA

\begin{abstract}
RESUMO: Os eventos ocasionados por chuvas extremas são as principais causas de inundações repentinas e deslizamentos de terra pelo mundo, dos quais em condições extremas de chuvas durante curtos períodos de tempo causam desastres. Portanto, o objetivo principal deste estudo foi analisar os efeitos do escoamento superficial de um evento extremo de chuva ocorrido em abril de 2018 na bacia do igarapé Paragominas, município homônimo, no nordeste do estado do Pará. E para a verificação das consequências desse evento foram analisados os anos de 1988 e 2018, de forma a permitir a identificação das alterações ocorridas na bacia, assim como avaliar o seu período de retorno. A estimativa do coeficiente de escoamento superficial (C) foi obtida a partir do registro do evento extremo de precipitação pluviométrica ocorrida entre os dias 11 e 12 de abril de 2018, em que os pluviógrafos indicaram que choveu $130 \mathrm{~mm}$ em 2 horas, ou seja, uma intensidade de $65 \mathrm{~mm} / \mathrm{h}$ resultando no rompimento de represas e o transbordamento do igarapé Paragominas. Para tanto foi aplicada a relação intensidadeduração-frequência - IDF, juntamente com a análise do hietograma de projeto a partir do método dos blocos alternados. Contudo, para a verificação das consequências desse evento foram analisados os anos de 1988 e 2018, de forma a permitir a identificação das alterações ocorridas na bacia. Como resultado obteve-se um tempo de retorno para esse evento extremo de 320 anos e um aumento de $23 \%$ nos valores $C$ entre os dois períodos analisados. Da mesma forma os hidrogramas de projeto mostraram variação considerável na distribuição do escoamento. Destaca-se a necessidade de repensar as lógicas de desenvolvimento seguidas, bem como planejar o crescimento da cidade, diante de seu uso e ocupação do solo, de forma que garanta maior capacidade de convivência com fenômenos climáticos extremos, cada vez mais frequentes
\end{abstract}

PALAVRAS-CHAVe: Eventos Extremos. Escoamento Superficial. Vazões de Projetos

ANALYSIS OF EFFECTS ON THE SURFACE DRAINING OF AN EXTREME RAIN EVENT IN A SMALL RURAL HYDROGRAPHIC BASIN OF THE AMAZON

ABSTRACT: The events caused by extreme rainfall are the main causes of flash floods and landslides around the world, of which in extreme rainfall conditions for short periods of time cause disasters. Therefore, this study aims to analyze the effects of runoff from an extreme rainfall event that occurred in April 2018 in the Paragominas river basin in northeastern Pará state. The estimate of the runoff coefficient (C) was obtained from the 
record of the extreme rainfall event that occurred between April 11 and 12, 2018, when rain gauge indicated that it rained $130 \mathrm{~mm}$ in 2 hours, i.e., an intensity of $65 \mathrm{~mm} / \mathrm{h}$ resulting in the rupture of dams and overflow of the Paragominas stream. For this purpose, the intensity-duration-frequency ratio - IDF - was applied, together with the analysis of the design hietogram from the alternating block method. However, to verify the consequences of this event, the years 1988 and 2018 were analyzed, in order to allow the identification of the changes that occurred in the basin. As a result, we obtained a return time for this extreme event of 320 years and a $23 \%$ increase in the $C$ values between the two analyzed periods. Similarly, the project hydrograms showed considerable variation in flow distribution. The need to rethink the development logics followed, as well as to plan the growth of the city, given its use and land occupation, in a way that ensures a greater capacity to coexist with extreme climatic phenomena, which are increasingly frequent.

KEYWORDS: Extreme Events. Surface Runoff. Project Flows.

\section{INTRODUÇÃO}

De acordo com Duarte et al (2015) e Sena et al. (2017), os eventos extremos consistem em ocorrências climatológicas fora do padrão de análise, ou seja, são considerados períodos de estiagem, alta frequência de secas, altas frequências de chuvas, chuvas extremas dentre outros. Estes eventos extremos têm afetado diversas cidades brasileiras causando múltiplos e constantes impactos, tais como: elevado número de mortes, feridos, desabrigados, proliferação de doenças, perdas econômicas, impactos ao meio ambiente, dentre outros (SENA et al., 2017).

Em bacias hidrográficas de pequeno porte e com rápida resposta às precipitações, diversos estudos foram desenvolvidos no âmbito da análise de eventos extremos de precipitação como os de Santos; Manzi (2010); Blain (2011); Junqueira Júnior et al. (2015); Oliveira; Silva (2016); Santos et al. (2017), e um dos mecanismos de avaliar esses eventos foi o uso das séries diárias, principalmente em função das mesmas apresentarem uma distribuição espacial e temporal mais densa e extensa.

Com isso, estes estudos denota a importância significativa no cotidiano das sociedades, quer seja por sua frequência e intensidade de ocorrência, quer seja pela vulnerabilidade socioambiental (SANTOS et al., 2017).

Os eventos ocasionados por chuvas extremas são as principais causas de inundações repentinas e deslizamentos de terra pelo mundo, dos quais em condições extremas de chuvas durante curtos períodos de tempo causam desastres (MODRICKA; GEORGAKAKOS, 2015; STALEY et al., 2015; REICHENBACH et al., 1998). Na Amazônia, diversos estudos como os de Zeng et al. (2008), Gloor et al. (2013) e Marengo et al. (2013) têm registrado uma alta frequência de secas e chuvas extremas durante as últimas décadas.

No atual contexto brasileiro, a análise dos extremos climáticos como o excesso ou a falta de chuva, seja por ondas de calor ou frio em diferentes regiões, desperta a atenção, devido as suas consequências, além dos inúmeros impactos que estavam ocasionando às populações mais vulneráveis, concentradas em áreas com solos impermeabilizados de difícil drenagem de águas pluviais, pouca concentração de áreas verdes e de grande ocupação de moradias desordenadas, tornando-se um alto risco para as mesmas (VALVERDE, 2017). 
Segundo Cardona (2004), a vulnerabilidade é a predisposição ou suscetibilidade física, econômica, política ou social que tem uma comunidade de ser afetada, ou de sofrer danos, caso um fenômeno desestabilizador de origem natural ou antrópico se manifeste. Ressalta-se que os eventos de chuvas extremas sempre existiram por si só, porém se constata que eles aumentaram em frequência e intensidade no contexto das mudanças climáticas, conforme pesquisas mais recentes, como as de Cantón et al. (2011), Chamizo et al. (2012), Jost et al. (2012) e IPCC (2014).

Os grandes volumes de precipitação pluviométrica fazem parte da Climatologia da região amazônica. Borma e Nobre (2013) enfatizam que os eventos extremos de chuva alteram significativamente a vazão dos rios e são frequentemente muito prejudiciais para o ritmo de vida da população amazônica. Essa concentração de chuvas resulta em consequências severas como o aumento na vazão dos rios e na frequência e magnitude dos deslizamentos de terrae,por isso, requer uma política que garanta uma ocupação adequada do solo, além de um melhor planejamento no sítio urbano, conforme Plano Diretor Urbano do município de Paragominas, Lei n 597/2006, Art. $2^{\circ}$ das Disposições Preliminares.

Desta forma, as equações de intensidade-duração-frequência (IDF) são frequentemente utilizadas em estudos hidrológicos com modelos chuva-vazão para determinar os fluxos de pico e os volumes de escoamento. Estas equações é uma ação dentro o Geodiversity Surveys Programme, cujo objetivo é reunir, consolidar e organizar os dados de precipitação coletados na rede meteorológica (CPRM, 2015).

As curvas IDF de chuva têm sido amplamente utilizadas na engenharia de recursos hídricos para avaliar o risco de inundação e a vulnerabilidade dos recursos hídricos, bem como para o projeto da estrutura hidráulica. Um grande número de estudos tem sido realizado para o desenvolvimento de curvas IDF em diferentes regiões do mundo (FERREIRA FILHO et al., 2019; BAIRWA et al., 2016; ELSEBAIE, 2012; OYEBANDE, 1982). Estes estudos são pautados em formulações para a caracterização de curvas IDF que possuem um padrão de parâmetros regionalizados de acordo com as caractesrísticas pluviográficas da área de estudo e foram desenvolvidas por Anniasingam et al. (1978), Chen (1983) e Koutsoyiannis et al. (1998).

Outro aspecto a ser considerado numa bacia hidrográfica é o solo. Desta forma, diversos modelos matemáticos e indicadores foram desenvolvidos para estimar a erosão do solo e avaliar os impactos ocasionados por eles, do ponto de vista das práticas de manejo, a equação de perda de solo (USLE) é a mais proeminente (KINNELL, 2010; OLIVEIRA et al., 2011).

As microbacias são importantes ferramentas de gestão, nas quais várias práticas são adotadas para preservar a água e o solo. Neste sentido, proteger ambos significam a adoção de diferentes técnicas de gestão, visando principalmente favorecer a infiltração da água da chuva no solo e fornece-a ao lençol freático, minimizando a erosão e evitando o escoamento superficial extremo na região (CORREA et al., 2018), assim, é importante não apenas empregar a gerência mas também conhecer e usar técnicas que, além de proporcionar um alto rendimento econômico, promove a proteção do solo, a fim de evitar o escoamento superficial e, consequentemente, evitar a ocorrência de erosão do solo. 
Portanto, o uso do solo desordenado é uma das variáveis que mais afetam os processos hidrológicos em bacias hidrográficas (MUÑOZ-ROBLES et al., 2011; MONTENEGRO et al., 2013). Em estudos mais recentes, as respostas hidrológicas das bacias encontraram maiores efeitos de eventos de precipitação de chuvas. Recentemente, em uma pesquisa na Noruega, Jost et al. (2012) avaliaram o efeito da vegetação sobre escoamento, e descobriram que árvore de espécies diferentes (cobertura vegetal) levam a diferentes escoamentos respostas, devido precipitação no mesmo tipo de solo.

Assim, as informações sobre a correlação entre estes fatores, como tipo de vegetação, precipitação e escoamento superficial, é importante para escolher a correta gestão da conservação da água e do solo numa bacia hidrográfica (PENG; WANG, 2012).

E para o conhecimento dos futuros processos de erosão do solo é muito importante para gerentes e tomadores de decisão (HAZBAVI; SADEGHI, 2016; DAVUDIRAD et al., 2016). Sadeghi et al. (2017) fazer uma previsão adequada da erosividade das chuvas e erosão do solo, porém essa etapa é difícil devido às incertezas que regem em relação às chuvas intensas, uma vez que elas podem variar de um dia para outro e ser aleatório e imprevisível.

Segundo site de notícias, G1 (2018), no dia 12 de abril, a cidade de Paragominas, sofreu com graves consequências, devido 0 alto índice pluviométrico. A principal consequência deste evento foi devido ao rompimento de represas que existem há mais de 30 anos e não têm licença para funcionar, resultando no alagamento de $40 \%$ da cidade de Paragominas, sudeste do estado.

Nesse contexto, o objetivo principal deste estudo foi analisar os efeitos do escoamento superficial de um evento extremo de chuva ocorrido em abril de 2018 na bacia do igarapé Paragominas, município homônimo, no nordeste do estado do Pará. E para a verificação das consequências desse evento foram analisados os anos de 1988 e 2018, de forma a permitir a identificação das alterações ocorridas na bacia, assim como avaliar o seu período de retorno.

\section{MATERIAL E MÉTODOS}

\section{LOCALIZAÇÃO E CARACTERIZAÇÃO DA ÁREA DE ESTUDO}

O município de Paragominas está localizado no nordeste paraense, inserido na mesorregião sudeste do estado, com sede localizada cerca de 320 km de distância da cidade de Belém, capital do estado do Pará (Figura 1). O município dispõe de uma área total de 19.309,09 km², o que corresponde a $1,5 \%$ do território paraense (PINTO et al., 2009), fundado às margens da Rodovia BR 010 (Belém-Brasília) e, de acordo com os dados do Instituo Brasileiro de Geografia e Estatística (IBGE, 2010), estima-se uma população de 97.819 habitantes para o ano de 2015. 


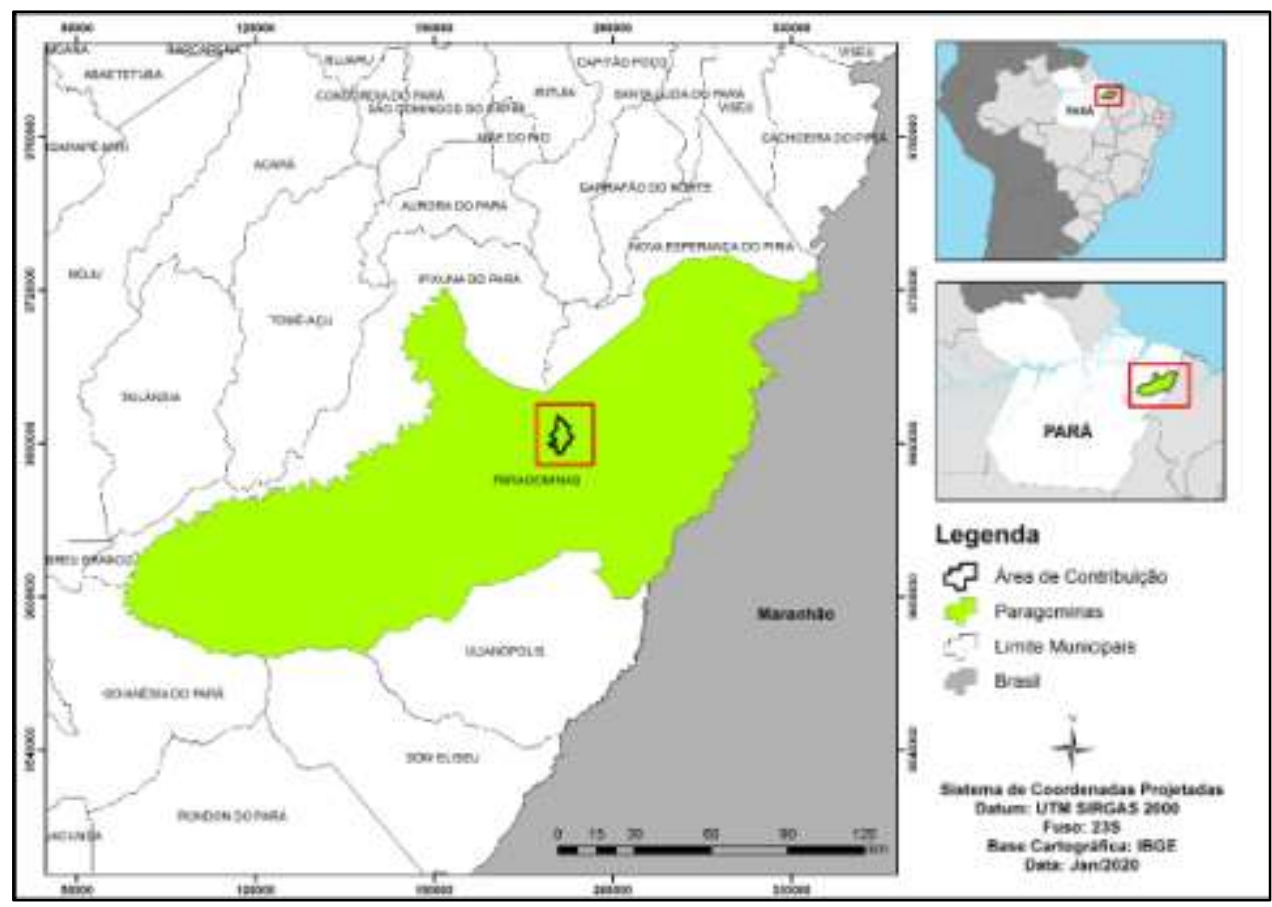

Figura 1 - Localização do município de Paragominas-PA.

De acordo com Martorano (2011), o município de Paragominas apresenta clima quente e úmido, com temperatura média anual de $26,3{ }^{\circ} \mathrm{C}$ e umidade relativa do ar em torno de $81 \%$. Bastos (2015) categorizou o município de Paragominas, conforme a classificação climática de Köppen, do tipo climático Aw (clima tropical chuvoso, com expressivo período de estiagem) e BlwA'a', e de acordo com a classificação de Thornthwaite, o clima é tropical úmido, com expressivo déficit hídrico.

O município apresenta umas médias anuais de precipitação pluvial chegam a $1.743 \mathrm{~mm}$, o mesmo tem um período chuvoso de dezembro a maio e outro de menor precipitação entre junho e novembro (MONTEIRO et al., 2009; ALVES, 2014). O mesmo apresenta 9 estações pluviométricas registradas pela Agência Nacional de Águas - ANA, porém, somente 5 destas possuem dados de série histórica de 30 anos, a citar, Estação Pluviométrica Cafezal, Fazenda Planalto, Fazenda Rural Zebu, Paragominas e Rio Capim, com códigos de estações: 00247005, 00347002, 00346001, 00347000 e 00247006, respectivamente. O climograma abaixo ilustra essas informações de uma forma resumida para o município. 


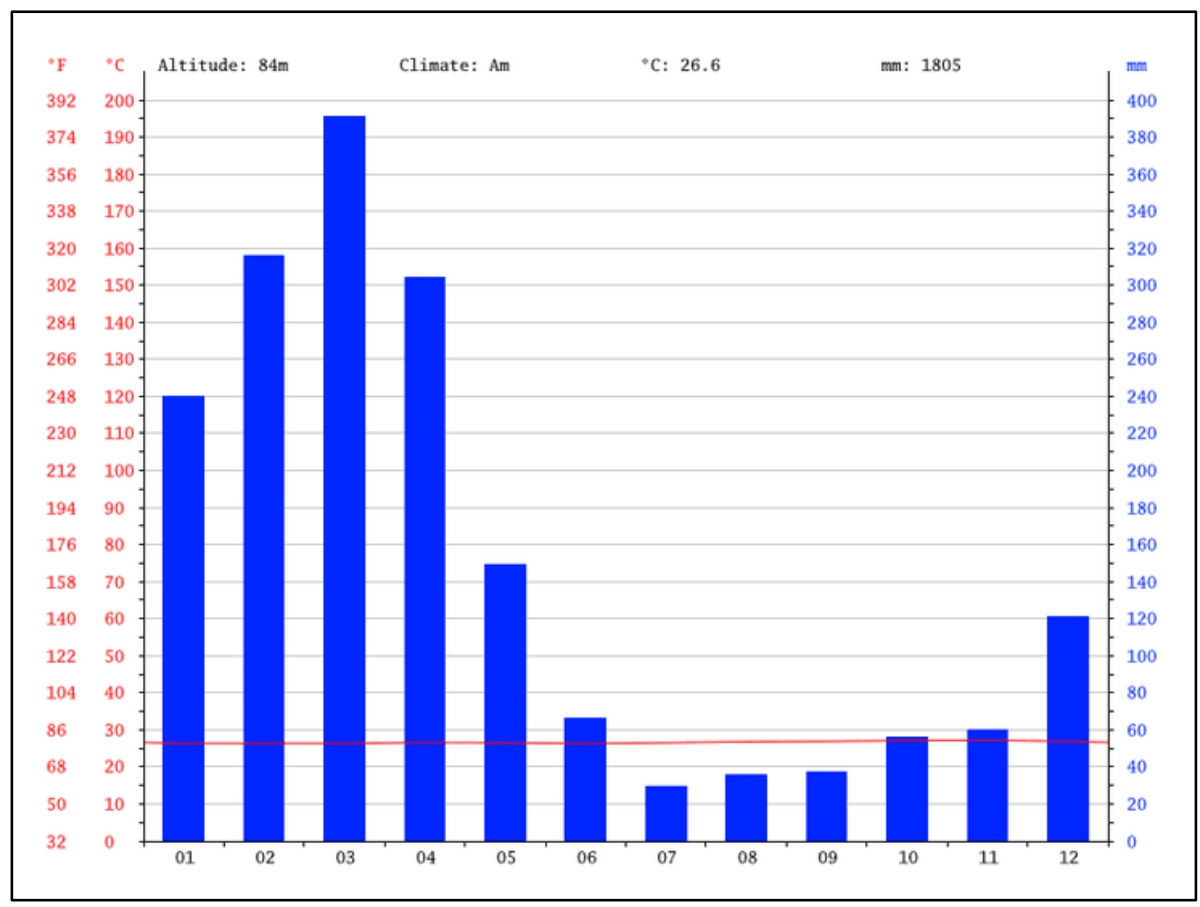

Figura 2 - Climograma do município de Paragominas.

A tratar do solo, que é uma das ferramentas importantes em estudos deste perfil, haja vista, que dependendo do tipo de solo, a taxa de infiltração da água pode ser maior ou menor, assim, a predominância do tipo de solo no município é o latossolo amarelo distrófico, que abrange $95 \%$ do território municipal (PINTO et al., 2009).

O igarapé Paragominas é um afluente do rio Uraim e possui suas áreas adjacentes predominantemente rurais. Diederichsen et al. (2017) informam que a bacia do rio Uraim é a responsável pelo abastecimento de água de $80 \%$ da população de Paragominas, encontra-se sob pressão de desmatamento, sendo que $45 \%$ da bacia já está desmatada e $55 \%$ possui cobertura florestal, os pequenos produtores representam $5 \%$ da bacia e os médios e grandes produtores representam $85 \%$ da bacia.

Na bacia hidrográfica do igarapé Paragominas estão localizadas 11 represas ao longo do curso d'água. A delimitação da bacia é apresentada na Figura 2. 


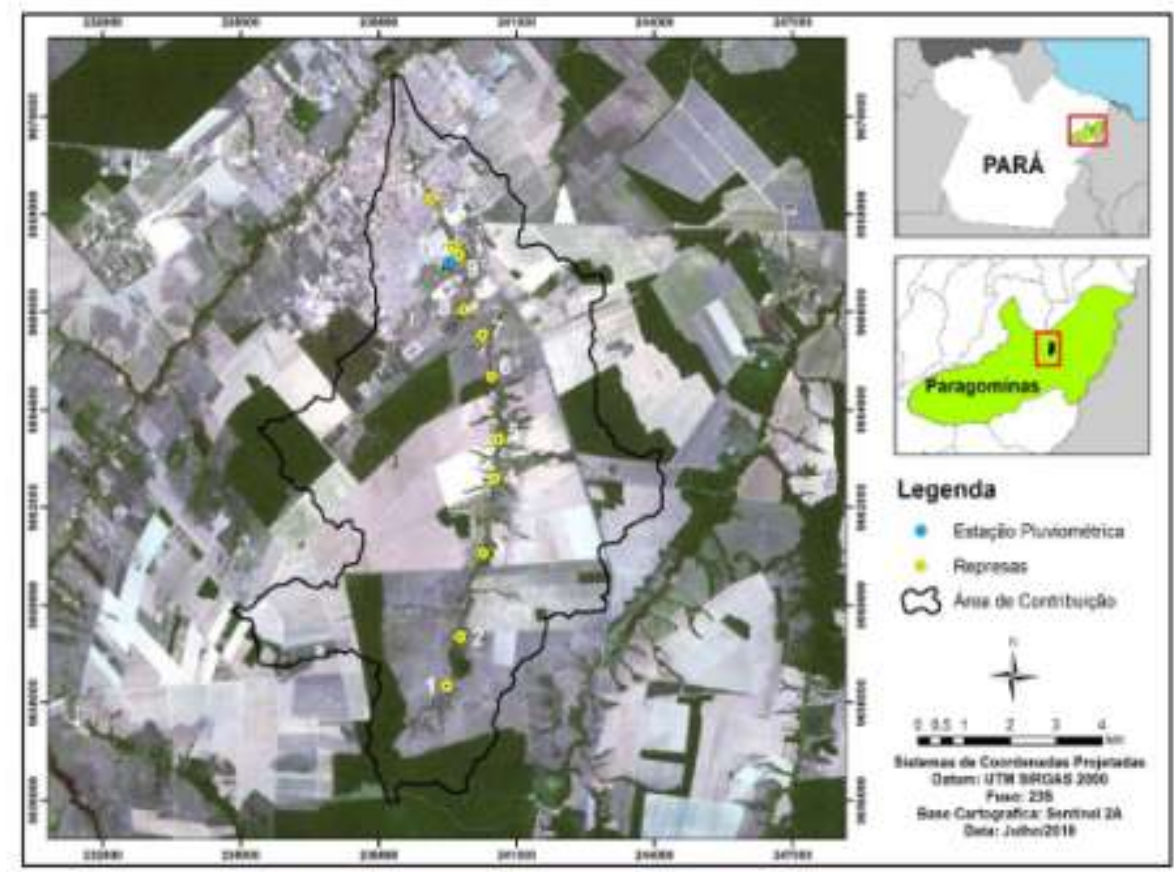

Figura 3 - Delimitação da bacia do Igarapé Paragominas e localização das barragens locais.

\section{ANÁLISE DO USO E COBERTURA DO SOLO}

De acordo com Genz e Tucci (1995), o recobrimento da superfície do terreno por obras de engenharia implica em uma maior quantidade e velocidade do escoamento superficial em um tempo menor, resultando no aumento da vazão de cheia, redução do tempo de concentração e diminuição da vazão de base, o que acarreta aumento das inundações.

Para definição das áreas de uso e cobertura do solo na bacia hidrográfica em estudo, foram delimitadas as superfícies utilizando as bandas (b5, b4 e b3) da imagem dos sensores TM/Landsat 5 com resolução espacial de $30 \mathrm{~m}$, e para o satélite Sentinel 2A foram utilizadas as bandas b2, b3 e b4 com resolução espacial de $10 \mathrm{~m}$. Sendo em seguida exportada para o software ArcGis 10.5, no qual foram elaboradas as composições coloridas em RGB (Red, Green, Blue). Esta composição de bandas foi utilizada por se tratar de uma bacia hidrográfica predominantemente rural, com atividades agropecuárias, classificando e quantificando as áreas em floresta, terras cultivadas, pastagens e áreas urbanas. Os arquivos de imagens utilizados foram referentes aos anos de 1988 e 2018 para o Landsat 5 e o Sentinel 2A, respectivamente, de forma a viabilizar a análise sobre a evolução do escoamento superficial na bacia em estudo.

\section{CÁLCULO DO COEFICIENTE DE ESCOAMENTO SUPERFICIAL (C)}

O cálculo do coeficiente de escoamento superficial foi obtido a partir do registro de um evento extremo (chuva) ocorrido entre os dias 11 e 12 de abril de 2018, em que os pluviógrafos indicaram que havia precipitado $130 \mathrm{~mm}$ em 2 horas, ou seja, uma intensidade de $65 \mathrm{~mm} / \mathrm{h}$ (POCCARD-CHAPUIS, 2018), que ocasionou o rompimento de represas e o transbordamento do igarapé 
Paragominas. Evento semelhante ocorreu na cidade de Fortaleza no dia 16 do mesmo mês e ano, com acumulado diário em torno de $90 \mathrm{~mm}$, provocando grandes transtornos à sociedade (MORAES; COUTINHO, 2019).

Com esse dado de precipitação, aplicou-se a relação de intensidadeduração-frequência (Equação 1), usando os parâmetros de ajustes relativos à localidade (k, a, b, c) obtidos em estudo realizado por Souza et al. (2012) para o município de Paragominas no qual usou uma série histórica de 24 anos de dados pluviométricos e assim obtendo o tempo de retorno desse evento extremo.

$I=\frac{k T_{r}^{a}}{\left(t_{d}+b\right)^{c}}$

Em que:

I: intensidade máxima média de precipitação $(\mathrm{mm} \mathrm{h-1)}$;

Tr: período de retorno (anos);

td: tempo de duração da chuva (min).

Assim, de acordo com Souza et al. (2012), os parâmetros K, A, B e C são, respectivamente, para o município de Paragominas: 1125.9005, 0.1232, $9.7922,0.7244$.

É usual que o valor empregado para o tempo de duração (td) de chuva seja equivalente ao tempo de concentração (Tc) da bacia hidrográfica, que é o tempo que leva a sua área hidrologicamente mais remota para contribuir com o fluxo de água em seu exutório (SOUZA; SOBREIRA, 2017), assim, considerando que ao atingir este tempo toda a bacia está contribuindo com a vazão máxima a qual está sujeita.

Para a estimativa do Tc foi adotada a equação de George Ribeiro (GARCEZ, 1967), conforme Equação 02.

$\mathrm{TC}=0,222 \cdot\left((1,05-0,2 \cdot \mathrm{p})^{-1}\right) \cdot\left(\mathrm{L} \cdot\left(\mathrm{S}^{-0,04}\right)\right)$

Em que $p$ representa a fração de área com mata em (\%); L é o comprimento do curso d'água principal em $(\mathrm{m})$ e $\mathrm{S}$ é a declividade média do curso d'água principal em $(\mathrm{m} / \mathrm{m})$.

Para a definição dos parâmetros como área da bacia $(A)$, comprimento (L) e declividade (S) do curso d'água principal foi utilizado um modelo digital de elevação (MDE), especificamente um Shuttle Radar Topography Mission (SRTM), arquivos "02s48_zn" e "03s48_zn", disponibilizado na base de dados do Serviço Geológico dos Estados Unidos (USGS) na plataforma Earth Explorer, com resolução espacial de 30m. A projeção foi definida de GCS_WGS1984 com referência geográfica para UTM Datum SIRGAS 2000 - Zona 23s (esta é a projeção plana onde se encontra maior parte de Paragominas-PA). Após a obtenção do SRTM, procedeu-se ao pré-processamento dos dados digitais de elevação e drenagem. A base de dados e as análises foram geradas por meio do sistema de informações geográficas, utilizando-se os softwares aplicados ao geoprocessamento, ArcGis 10.5. 
A obtenção da série do coeficiente $C$ em função do tempo de retorno ( $T r)$ do evento extremo, intensidades pluviométricas (I), precipitação (p) e precipitação efetiva (pe), considerou-se a relação entre o armazenamento máximo, S (mm); as precipitações máximas acumuladas, $\mathrm{P}(\mathrm{mm})$; a precipitação efetiva acumulada, $\mathrm{Pe}(\mathrm{mm})$; a quantidade armazenada no instante $(\mathrm{P}-\mathrm{Pe})$; as abstrações iniciais, Ia, $(0,2 \times \mathrm{S})$ e o parâmetro curva número, $\mathrm{CN}$; segundo a metodologia utilizada, a precipitação efetiva foi obtida pelas seguintes relações:

$$
\begin{aligned}
& P_{e}=\frac{\left(P-I_{a}\right)^{2}}{P-I_{a}+S} \\
& S=\frac{25400}{C N}-254 \\
& C=\frac{(P-0,2 S)^{2}}{(P+0,8 S)^{\frac{1}{P}}}
\end{aligned}
$$

Gribbin (2009) cita que o Método NRCS (National Resources Conservation Service) é um dos procedimentos para calcular um hidrograma sintético, baseado em fatores empiricamente determinados, desenvolvido pelo Serviço de Conservação dos Recursos Naturais do Departamento de Agricultura do Estados Unidos da América. Neste trabalho, decidiu-se utilizar este método para o tempo de concentração, para pequenas bacias rurais com área entre 2 a $5000 \mathrm{~km}^{2}$, pois a área da bacia do igarapé Paragominas se enquadra na característica rural, pois possui $65,69 \mathrm{~km}^{2}$.

Segundo Soares et al. (2017), o método Número de Curva (CN) é muito utilizado para estimar vazões em pequenas bacias com base em dados que podem ser derivados de sensoriamento remoto e Sistemas de Informação Geográfica. As classes mais impermeáveis apresentam CN mais elevados e, portanto, indicam menor potencial de infiltração e maior escoamento superficial da água. O CN é um valor tabelado que descreve a combinação de tipo de solo, a umidade antecedente, o uso e cobertura na bacia.

O método NRCS (2007) apresenta valores de CN variando entre 0 e 100 e dependendo do tipo de solo, das condições de ocupação e da umidade antecedente. Os grupos hidrológicos de solos ( $A, B, C$ e D) apresentam as seguintes características:

Grupo A - Solos que produzem baixo escoamento superficial e alta infiltração (arenosos com baixo teor de argila total, inferior a $8 \%$ );

Grupo B - Solos menos permeáveis que o anterior, arenosos menos profundos que os do Grupo A e com permeabilidade superior à média (teor de argila ainda inferior a $15 \%)$;

Grupo C - Solos que geram escoamento superficial acima da média e com capacidade de infiltração abaixo da média, contendo considerável porcentagem de argila e pouco profundo (barrentos com teor total de argila de 20 a $30 \%$ mas sem camadas argilosas impermeáveis ou contendo pedras até profundidades de 1,2 m); 
Grupo D - Solos contendo argilas expansivas e poucos profundos com muito baixa capacidade de infiltração e alta capacidade de escoamento (argilosos 30 $40 \%$ de argila e ainda com camada densificada a uns $50 \mathrm{~cm}$ de profundidade).

O grupo hidrológico do solo, em conjunto com o uso e cobertura do solo, fornece o valor do $\mathrm{CN}$ a ser utilizado no método. No caso da bacia do igarapé Paragominas, o grupo hidrológico mais presente foi o grupo B. Assim, foi possível fazer uma estimativa do CN unificado para a bacia, a partir dos percentuais já obtidos de uso e cobertura do solo.

$\mathrm{Na}$ medida em que uma bacia vai sendo urbanizada, também vai ocorrendo o aumento do escoamento superficial. Como resultado do aumento da impermeabilização, uma maior parcela da precipitação se transforma em escoamento na bacia e com isso aumenta o valor do coeficiente de escoamento superficial (C). Dessa forma, o coeficiente C é de grande importância na avaliação da capacidade de sistemas de drenagens.

Os valores de CN em função da cobertura e do tipo hidrológico de solo (condição II de umidade) são apresentados na Tabela 1.

Tabela 1 - Valores de CN em função da cobertura e do tipo hidrológico do solo.

\begin{tabular}{|c|c|c|c|c|}
\hline \multirow{2}{*}{$\begin{array}{l}\text { Tipo de uso do } \\
\text { solo/Tratamento/Condições hidrológicas }\end{array}$} & \multicolumn{4}{|c|}{ Grupo do Solo } \\
\hline & $\mathbf{A}$ & B & $\mathbf{C}$ & D \\
\hline Uso residencial & & & & \\
\hline Tamanho médio do lote - \% Impermeável & & & & \\
\hline Até $500 m^{2}-65$ & 77 & 85 & 90 & 92 \\
\hline $1000 m^{2}-38$ & 61 & 75 & 83 & 87 \\
\hline $1500 m^{2}-30$ & 57 & 72 & 81 & 86 \\
\hline Estacionamentos pavimentados, telhados & 98 & 98 & 98 & 98 \\
\hline Ruas e estradas & & & & \\
\hline Pavimentadas, com guias e drenagem & 98 & 98 & 98 & 98 \\
\hline Com cascalho & 76 & 85 & 89 & 91 \\
\hline De terra & 72 & 82 & 87 & 89 \\
\hline $\begin{array}{l}\text { Áreas comerciais ( } 85 \% \text { de } \\
\text { impermeabilização) }\end{array}$ & 89 & 92 & 94 & 95 \\
\hline $\begin{array}{l}\text { Distritos industriais ( } 72 \% \text { de } \\
\text { impermeabilização) }\end{array}$ & 81 & 88 & 91 & 93 \\
\hline Espaços abertos, parques, jardins: & & & & \\
\hline Boas condições, cobertura de grama > 75\% & 39 & 61 & 74 & 80 \\
\hline $\begin{array}{l}\text { Condições médias, cobertura de grama > } \\
50 \%\end{array}$ & 49 & 69 & 79 & 84 \\
\hline $\begin{array}{l}\text { Terreno preparado para plantio, descoberto } \\
\text { Plantio em linha reta }\end{array}$ & 77 & 86 & 91 & 94 \\
\hline Cultura em fileira & & & & \\
\hline Linha reta condições ruins & 72 & 81 & 88 & 91 \\
\hline Linha reta condições boas & 67 & 78 & 85 & 89 \\
\hline Curva de nível condições ruins & 70 & 79 & 84 & 88 \\
\hline Curva de nível condições boas & 65 & 75 & 82 & 86 \\
\hline Cultura de grãos & & & & \\
\hline Linha reta condições ruins & 65 & 76 & 84 & 88 \\
\hline Linha reta condições boas & 63 & 75 & 83 & 87 \\
\hline Curva de nível condições ruins & 63 & 74 & 82 & 85 \\
\hline Curva de nível condições boas & 61 & 73 & 81 & 84 \\
\hline
\end{tabular}




\begin{tabular}{l|c|c|c|c}
\hline Tipo de uso do & \multicolumn{4}{|c}{ Grupo do Solo } \\
\cline { 2 - 5 } solo/Tratamento/Condições hidrológicas & A & B & C & D \\
\hline Pastos & & & & \\
Condições ruins & 68 & 79 & 86 & 89 \\
Condições médias & 49 & 69 & 79 & 84 \\
Condições boas & 39 & 61 & 74 & 80 \\
Curva de nível condições ruins & 47 & 67 & 81 & 88 \\
Curva de nível condições médias & 25 & 59 & 75 & 83 \\
Curva de nível condições boas & 6 & 35 & 70 & 79 \\
\hline Campos em condições boas & 30 & 58 & 71 & 78 \\
\hline Florestas condições ruins & 45 & 66 & 77 & 83 \\
Florestas condições médias & 36 & 60 & 73 & 79 \\
Florestas condições boas & 25 & 55 & 70 & 77 \\
\hline
\end{tabular}

Fonte: Bollman; Marques (2001).

Os valores constantes na Tabela 1 referem-se a condições médias de umidade antecedente (condição II). A conversão dos valores de CN para condição I ou III, dependendo da situação que se desejar representar, é realizada conforme se apresenta na Tabela 2. A condição I representa solos secos, e a condição III representa a situação em que o solo está saturado.

Tabela 2 - Conversão do Valor de CN para as condições I, II ou III.

\begin{tabular}{c|c|c}
\hline \multicolumn{3}{|c}{ Condições de umidade } \\
\hline I & II & III \\
\hline 100 & 100 & 100 \\
\hline 87 & 95 & 99 \\
\hline 78 & 90 & 98 \\
\hline 70 & 85 & 97 \\
\hline 63 & 80 & 94 \\
\hline 57 & 75 & 91 \\
\hline 51 & 70 & 87 \\
\hline 45 & 65 & 83 \\
\hline 40 & 60 & 79 \\
\hline 35 & 55 & 75 \\
\hline 31 & 50 & 70 \\
\hline 27 & 45 & 65 \\
\hline 23 & 40 & 60 \\
\hline 19 & 35 & 55 \\
\hline 15 & 30 & 50 \\
\hline
\end{tabular}

Fonte: Bollman; Marques (2001).

\section{HIETOGRAMA dE PROJETO EFETIVO E VAZÃo dE PROJETO}

Na determinação do hietograma de projeto efetivo foi aplicado o método do Soil Conservation Service do Departamento de Agricultura dos Estados Unidos (SCS, 1972; SING et al., 2008), cujo nome novo é NRCS (National Resources Conservation Service), o qual considera os seguintes critérios:

a) Obtenção da lâmina efetiva para cada duração (Equações 3 e 4);

b) Cálculo dos incrementos da lâmina efetiva acumulada, por intervalo de tempo; 
c) Aplicação dos parâmetros estimados para o município de Paragominas (k, a, b, c) da relação IDF por Souza et al. (2012);

d) Demais parâmetros obtidos do hidrograma unitário sintético triangular do SCS.

Os parâmetros do hidrograma de projetos aplicados ao estudo foram estimados a partir do hidrograma unitário sintético triangular do SCS (1972), cuja metodologia consistiu, inicialmente, da estimativa do Hidrograma Unitário Curvilíneo da área em estudo, adotando-se as equações apresentadas no Quadro 1.

Quadro 1 - Variáveis do Hidrograma Unitário Sintético.

\begin{tabular}{|ccl|}
\hline $\mathbf{N}^{\circ}$ Eq. & \multicolumn{1}{c|}{ Equação } & \multicolumn{1}{c|}{ Definição } \\
\hline 06 & $t d=0,20 t c$ & $\begin{array}{l}\text { Tc: tempo de concentração estimado } \\
\text { utilizando-se a equação de George } \\
\text { Ribeiro }\end{array}$ \\
\hline 07 & $T_{p}=(\mathrm{D} \cdot 0,5)+\left(t_{c} \cdot 0,6\right)$ & $\begin{array}{l}T_{p}: \text { tempo de instante de pico }(\mathrm{h}) \\
\mathrm{D}: \text { duração da chuva unitária; } \\
\text { tc: tempo de concentração }\end{array}$ \\
\hline 08 & $t_{b}=2,67 \cdot T_{p}$ & tb: tempo de base \\
\hline 09 & $t_{r}=1,67 \cdot T_{p}$ & \begin{tabular}{l}
$t_{r}:$ tempo de retardo \\
\hline 10
\end{tabular} \\
$Q_{p}=2,08 \cdot P \cdot A / T_{p}$ & $\begin{array}{l}\text { Qp: vazão de pico }\left(\mathrm{m}^{3} / \mathrm{s} . \mathrm{cm}\right) \\
\text { A: área }\left(\mathrm{km}^{2}\right)\end{array}$ \\
\hline
\end{tabular}

Com os valores obtidos de Tp e Qp, foram definidas as ordenadas do Hidrograma Unitário da Área, por meio do Hidrograma Unitário Adimensional (SCS, 1972). Para a estimativa do hidrograma de escoamento superficial foram utilizadas as ordenadas do hidrograma unitário e os valores de precipitação excedentes obtidos a partir dos hietogramas efetivos.

Em seguida foi determinado o hietograma de projeto utilizando-se a equação de chuvas intensas do município de Paragominas (SOUZA, 2012) a partir do método dos blocos alternados (MARCELLINI, 1994), cujas etapas consistem em:

a) Seleção da duração total da precipitação (td) e do intervalo de discretização $(\Delta \mathrm{t})$;

b) Obtenção da intensidade de precipitação para cada duração, a partir da relação IDF, obtida por Souza et al. (2012);

c) Transformação das intensidades em alturas de precipitação e acumuladas até o último intervalo de tempo;

d) Cálculo dos incrementos dos totais acumulados por intervalo;

e) Rearranjo dos incrementos ou blocos, obtidos em uma sequência tal que, no centro da duração da precipitação, se situe o bloco maior e, em seguida, os demais.

f) As equações aplicadas são mostradas na Tabela 3. 
Tabela 3 - Equações Aplicadas no Hietograma.

\begin{tabular}{|c|c|}
\hline Parâmetros & Equações \\
\hline td (h) & $\Delta \mathrm{t}$ \\
\hline $\mathbf{T}(\mathbf{h})$ & $\Delta t^{*} 60$ \\
\hline$P(\mathbf{m m})$ & Precipitação do rearranjo dos incrementos \\
\hline$P$ acum $(\mathbf{m m})$ & $P_{\text {acum }}=P+P_{\text {acum }}$ \\
\hline Pef acum (mm) & Equação 3 \\
\hline Inf acum (mm) & Inf acum $_{\text {acum }}=P_{\text {acum }}-P_{\text {efacum }}$ \\
\hline Pef (mm) & $P_{e f}=P_{\text {acum.posterior }}-P_{\text {acum.anterior }}$ \\
\hline Inf ( $\mathbf{m m})$ & $\operatorname{Inf}=\operatorname{Inf} f_{\text {acum.posterior }}-P \operatorname{In} f_{\text {acum.anterior }}$ \\
\hline
\end{tabular}

\section{RESULTADOS E DISCUSSÃO}

As características resultantes da análise de uso e cobertura do solo para bacia hidrográfica do igarapé Paragominas nos anos de 1988 e 2018, considerando a declividade média de 3,51\%, apresentou resultados conforme Tabela 4. Em que se observa um incremento nas áreas urbanas e de agricultura acima de $100 \%$ e $200 \%$ respectivamente, quando comparado os dois anos de estudo.

Tabela 4 - Uso e cobertura do solo na bacia hidrográfica do Igarapé Paragominas.

\begin{tabular}{cccc}
\hline Classificação & \multicolumn{2}{c}{ Áreas $\left.\mathbf{( k m}^{\mathbf{2}}\right)$} & Aumento \\
& 1988 & 2018 & $\%$ \\
\hline Área urbana & $\mathbf{3 . 5 3}$ & $\mathbf{7 . 1 5}$ & $\mathbf{1 0 2 . 3 5 \%}$ \\
\hline Agricultura & $\mathbf{7 . 7 1}$ & 27.71 & $\mathbf{2 5 9 . 2 7 \%}$ \\
\hline Floresta & $\mathbf{3 7 . 2 4}$ & 14.23 & $\mathbf{- 6 1 . 8 0 \%}$ \\
\hline Pastagem & $\mathbf{1 6 . 4 0}$ & 15.80 & $\mathbf{- 3 . 6 7 \%}$ \\
\hline Corpo hídrico & $\mathbf{0 . 8 0 2}$ & 0.802 & - \\
\hline
\end{tabular}

A análise de incrementos mostra a abrangência das atividades de agricultura na bacia, seguida pelo aumento de áreas urbanizadas. A redução das áreas ocupadas por florestas foi significativa. As áreas de pastagem apresentaram redução discreta entre os períodos analisados. Essas áreas são definidas nas Figuras 4 e 5, em que permite suas comparações nos dois anos avaliados, mostrando o quanto a bacia foi antropisada pela agricultura e a expansão da malha urbana, enquanto que a de floresta diminui, podendo relacionar com o aumento da área agricultável, uma vez que a alteração nessas áreas foram proporcionais. 


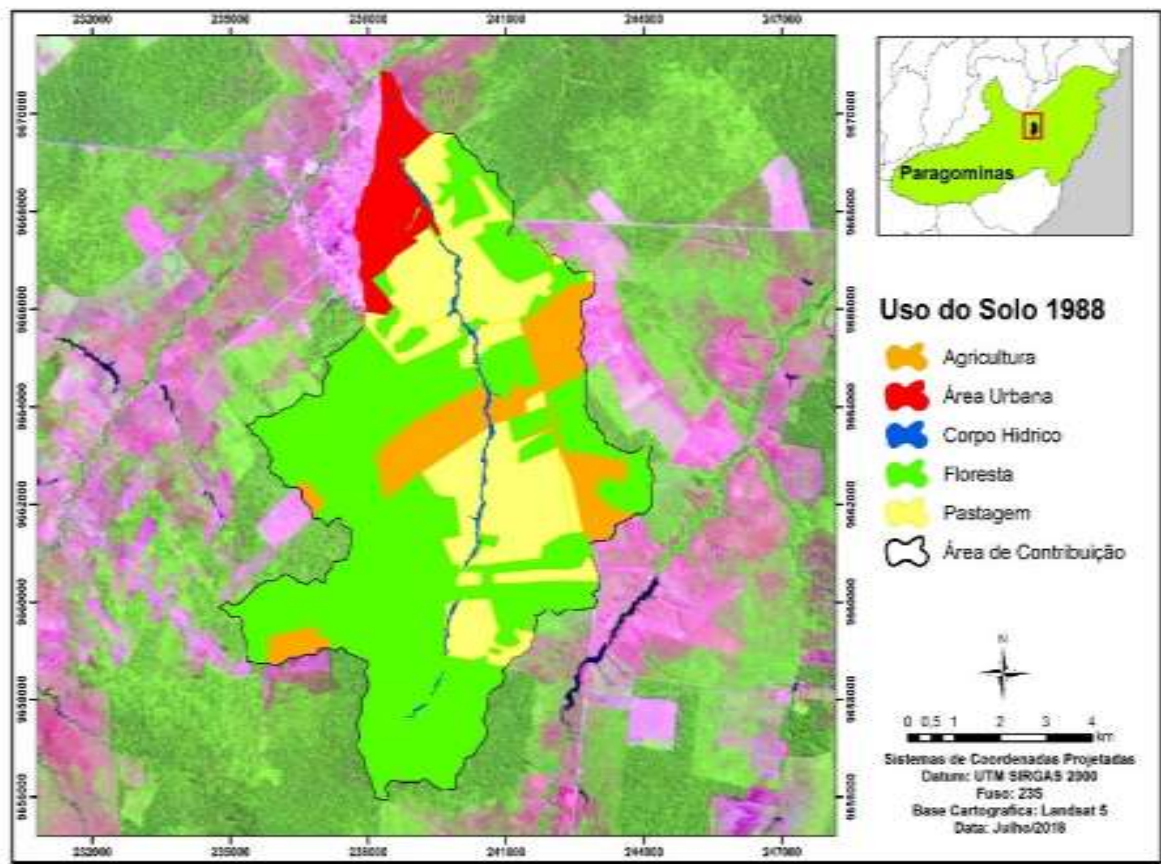

Figuras 4 - Uso do solo na bacia do Igarapé Paragominas no ano de 1988.

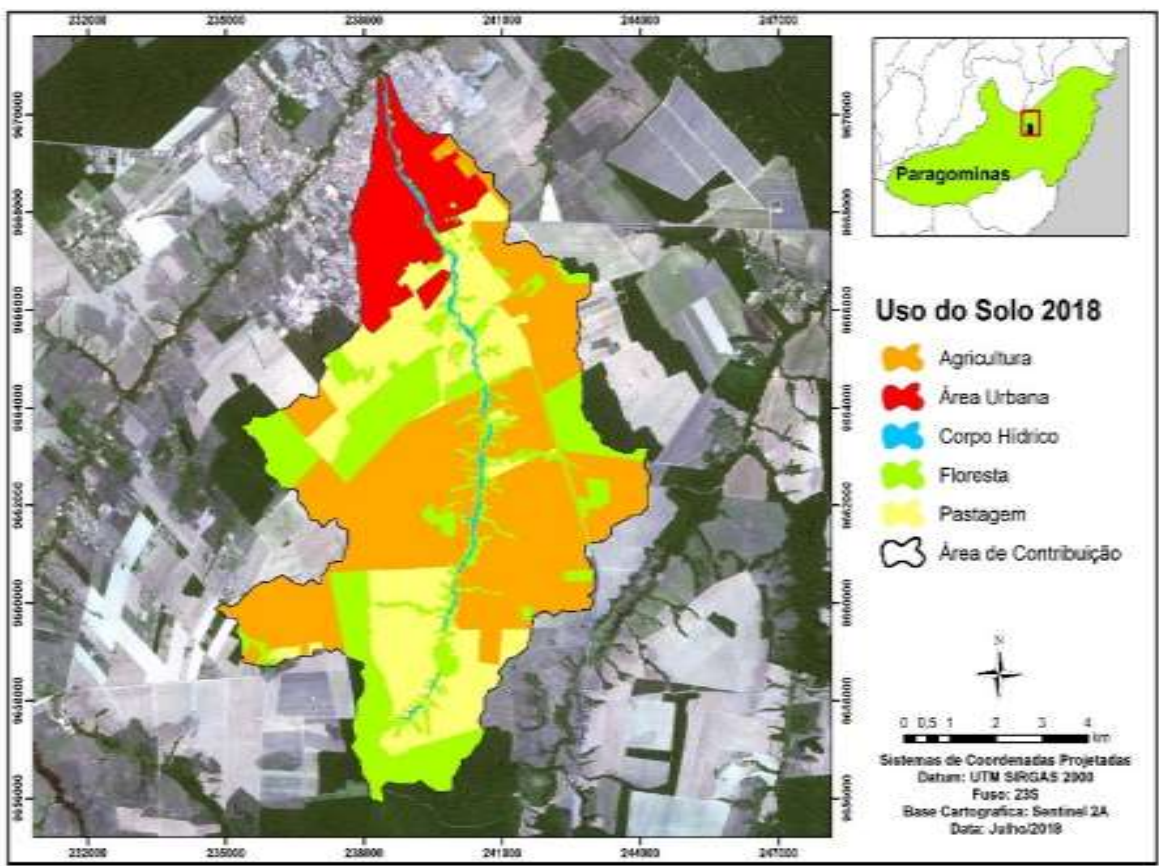

Figuras 5 - Uso do solo na bacia do Igarapé Paragominas no ano de 2018.

As figuras ainda mostram a agricultura ocupando as áreas que antes se desenvolvia a pastagem. A análise desses atributos teve por objetivo principal a obtenção dos indicadores qualitativos do uso e ocupação do solo que pudessem ser associados a outros estudos complementares relacionados ao diagnóstico do meio físico. 
Estes resultados evidenciam uma mudança no uso e ocupação do solo na bacia, não distante do que se apresentam em outras regiões do país, como em estudo realizado por Garcia, Miyamoto e Maia (2018), para a bacia do rio Jundiaí em São Paulo, onde, como consequências do elevado grau de urbanização da BRJ incluem a perda da cobertura vegetal, redução da taxa de infiltração da água, aumento da impermeabilização do solo, do escoamento superficial e das vazões máximas, redução do escoamento subsuperficial e subterrâneo e da evapotranspiração.

Em uma análise análoga, Rodrigues et al. (2018), verificaram a evolução do uso e cobertura do solo na bacia hidrográfica rural do igarapé da Prata, também no nordeste paraense, entre 1984 e 2010, constatando alterações menos acentudas do que os resultados apresentados para a bacia do igarapé Paragominas, onde houve reduções das áreas de matas $(-3,60 \%)$ e terras cultivadas $(-13,70 \%)$, e aumento nas áreas de pastagem $(17,30 \%)$.

De Castro, Rodrigues e Ferreira Filho (2019) estimaram o coeficiente de escoamento superficial na área de drenagem dos lagos Bolonha e Água Preta, localizados nos municípios de Belém e Ananindeua, Estado do Pará. Para tanto, inicialmente se utilizou de imagens de um Modelo Digital de Elevação. Assim, estimou-se o coeficiente de runoff por valores encontrados na literatura e pelo método NRCS, utilizando como base uma equação local de chuvas intensas e valores de Número de Curva (CN) para a discriminação das áreas no ano de 2018. Logo, esta pesquisa teve como resultados, pelo método NRCS, foram alcançados valores de C que variam numa faixa entre 0,169 a 0,321, dependendo do período de retorno da precipitação local numa faixa de 1 a 150 anos, e como conclusão, os referidos autores atualizaram o estudo destes lagos.

Os valores de $\mathrm{CN}$ foram estimados utilizando os resultados obtidos de uso e cobertura do solo para os anos 1988 e 2018, este último ano foi escolhido por se tratar da situação mais recente, portanto, mais representativa das condições atuais da bacia estudada. Os valores de CN em função da cobertura e do tipo hidrológico de solo são apresentados na Figura 6.

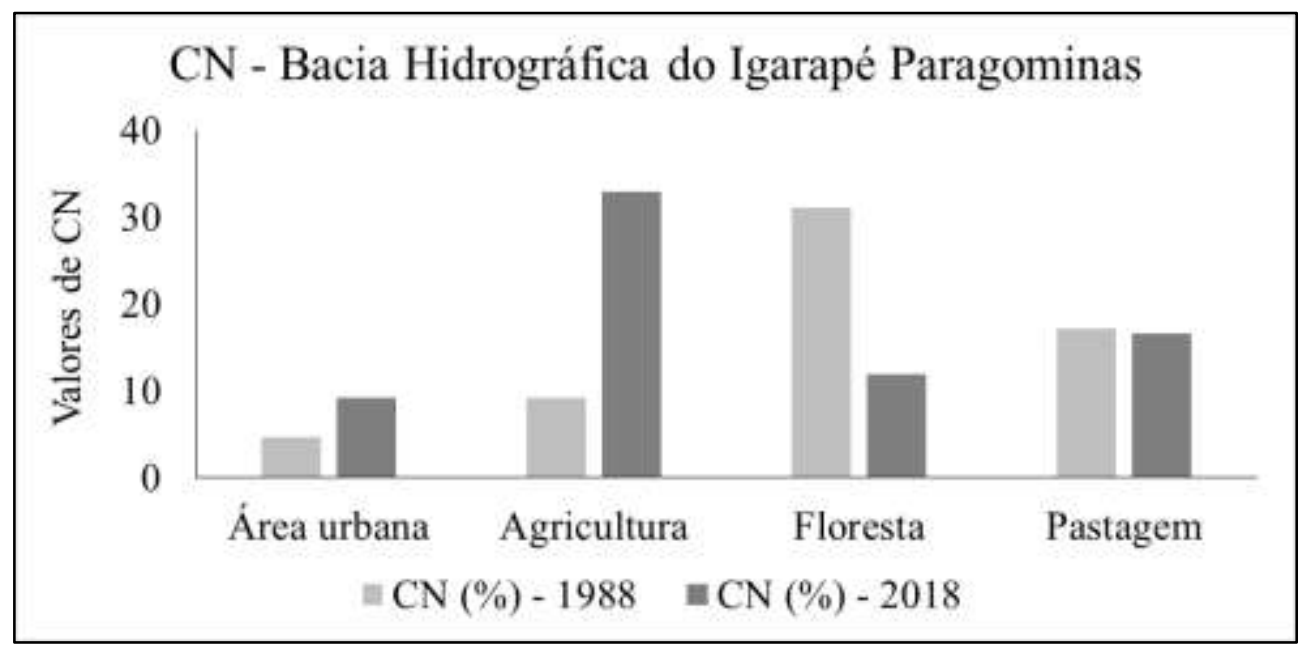

Figura 6 - CN para a Bacia hidrográfica do igarapé Paragominas.

A característica rural da bacia do igarapé Paragominas é predominante. Os valores de $\mathrm{CN}$ para áreas urbanizadas aumentaram e para áreas de florestas reduziram, refletindo em redução nessas áreas do Potencial de Infltração (S). A 
expansão das atividades agrícolas também potencializam a redução da infiltração da água no solo, uma vez que o parâmetro CN por ser muito sensível, qualquer variação em seu valor resulta em grandes alterações nos volumes escoados e nos picos dos hidrogramas.

Targa et al. (2012) verificaram a evolução do potencial de infiltração em uma bacia urbana de Belém-PA e mostram que a expansão das áreas urbanas sob áreas verdes (matas) é diretamente relacionada ao aumento dos valores de $\mathrm{CN}$ e consequentemente à redução da capacidade de infiltração do solo, aumentando o escoamento superficial. Para Matos et al. (2011), a evolução da urbanização na bacia do Igarapé Tucunduba ocasionou o adensamento populacional e a consequente redução de $755 \%$ na área de vegetação do Igarapé, no período de 1972 para 2006.

Cunha et al. (2014) realizaram uma investigação de vazões extremas ocorridas entre 9 e 14 de abril de 2011 na bacia do Rio Araguari(AP) e verificaram em uma vazão máxima recorde de $4036 \mathrm{m3} / \mathrm{s}$, e concluiu-se que tais eventos extremos são pouco detectáveis e oferecem riscos consideráveis aos usuários da bacia. No estudo dos autores, a previsão de vazão, baseada na série hidrológica disponível, era de 100 anos de retorno, mas as análises revelaram que este período seria de 360 anos, semelhante aos resultados desta pesquisa, indicando significativa fragilidade do sistema de previsão de eventos extremos no estado do Amapá.

Por meio da equação de George Ribeiro, o tempo de concentração da bacia do igarapé Paragominas foi estimado em 4,03 h (2018). De posse das informações pluviométricas do evento extremo ocorrido, associadas a equação de chuva intensa de Paragominas, constatou-se que o período de retorno de uma chuva com intensidade de $67,5 \mathrm{~mm} / \mathrm{h}$, com duração de 120 minutos é de 320 anos. Bem como aplicando o método NRCS foram alcançados valores de C, para diferentes períodos de retorno, como também para os demais parâmetros da bacia, conforme apresentado na Tabela 5.

Tabela 5 - Parâmetros característicos do uso e ocupação do solo da bacia hidrográfica.

\begin{tabular}{|c|c|c|c|}
\hline & Parâmetros & 1988 & 2018 \\
\hline $\mathbf{C N}$ & & 62,93 & 71,53 \\
\hline $\mathbf{S}(\mathrm{mm})$ & & 149,61 & 101,07 \\
\hline Tc (min.) & & 260,21 & 242,05 \\
\hline
\end{tabular}

Os eventos pluviais extremos como esse resultam em prejuizos à sociedade, como as chuvas intensas que atingiu o estado de Pernambuco nos dias 16, 17 e 18 de junho de 2010, foi de magnitude severa, com várias cidades inundadas, e milhares de pessoas desabrigadas, com registro de dezenas de mortes. junho de 2010, provocando inundações e grandes prejuízos humanos e econômicos (ALVES et al., 2013). Outro evento da mesma magnitude ocorreu em novembro de 2008, na região do litoral centro-norte do Estado de Santa Catarina foi registrada a ocorrência de um evento pluvial extremo que gerou grandes prejuízos materiais e humanos (CEDEC-SC, 2009).

A determinação do tempo de concentração da bacia hidrográfica do igarape Paragominas, além de auxiliar na definição da vazão máxima a que está 
sujeita uma bacia, também contribuirá para a formulação de ações preventivas envolvendo, principalmente, as áreas ocupadas ao longo do curso d'água, onde a ocorrência de processos de inundação é conhecida, visto que chuvas com durações iguais ou maiores que o tempo de concentração da bacia indicarão que quando o volume precipitado nas regiões mais distantes chegarem à foz, ou aos pontos de interesse, ele vai se somar com o volume precipitado nestas regiões, causando uma cheia maior do que a de uma chuva mais curta.

A chuva intensa da noite entre os dias 11 e 12 de abril de 2018 no munciipio de Paragominas, devido às características de uso e cobertura do solo, gerou um escoamento superficial com $C$ igual a 0,45. Comparado ao ano de 1988, com as características de uso e cobertura do solo para aquele período, um evento pluviométrico com as mesmas características resultariam em um $C$ de 0,32 . Considerando as alterações no uso e cobertura do solo entre os anos de 1988 e 2018, pode-se afirmar que houve um aumento de 40,6\% no escoamento superficial da bacia. Na Figura 7 mostra-se a evolução do coeficiente C para a bacia considerando chuvas com a duração igual ao tempo de concentração e com duração igual aos 120 minutos de acordo com o evento pluviométrico estudado.

\section{Coeficiente de Escoamento Superficial}

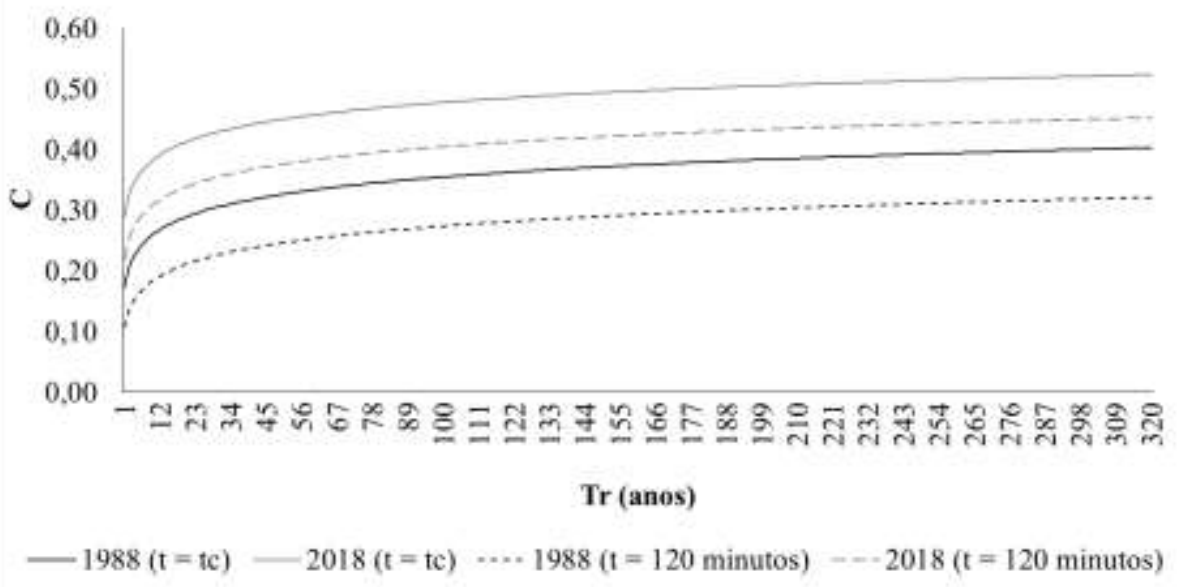

Figura 7 - Coeficiente de escoamento superficial para diferentes Tr.

A variação do coeficiente $C$ determinado para os anos em estudo mostra que o uso e cobertura do solo modificaram significativamente o padrão de escoamento da bacia. Logo a contribuição relacionada à determinação das chuvas intensas e tempos de concentração na caracterização da bacia hidrográfica do igarapé Paragominas serve de auxílio no desenvolvimento e implementação de sistemas de monitoramento de desastres naturais ao longo do seu território e entorno, por meio da instalação de instrumentos de monitoramento dos eventos.

As modificações ocorridas no padrão de escoamento da bacia hidrográfica podem ser relacionado com os hietogramas, os quais refletem as características da bacia hidrográfica do igarapé Paragominas, com área de $65,69 \mathrm{~km}^{2}$, que é tipicamente rural, no ano de 2018 com 14,22\% de áreas verdes preservadas e 11 represas ao longo de seu curso d'água, que certamente alteram seu regime hídrico. 
As Figuras 8 e 9 apresentam os hietogramas de projeto, excedência, infiltrado, acumulado, excedência acumulado e infiltrado acumulado, para o tempo de retorno de 320 anos, característico da chuva intensa ocorrida no dia 12 de abril de 2018, para os dois anos avaliados, além disso, as figuras indicam como a precipitação desse acontecimento pluvioso intenso foi distribuída ao longo do tempo.

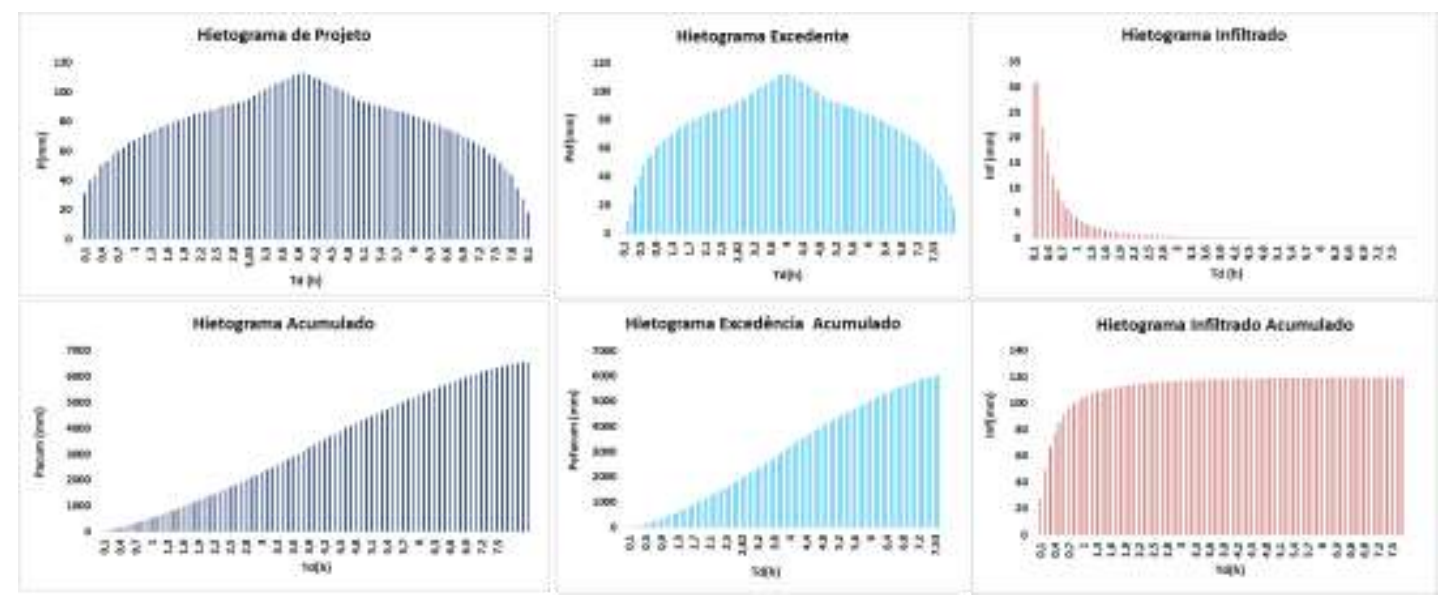

Figura 8 - Hietogramas para precipitações com $\operatorname{Tr} 320$ anos - Ano 1988.
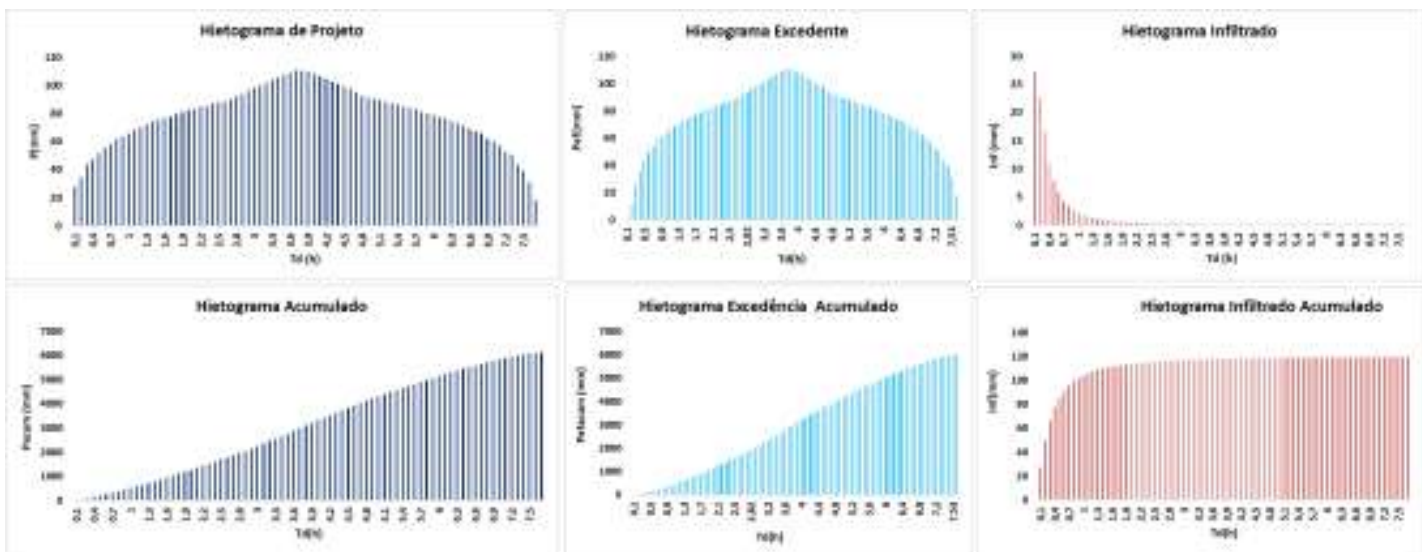

Figura 9 - Hietogramas para precipitações com Tr 320 anos - Ano 2018.

Observando as Figuras 8, 9 e 11, percebe-se que há uma coerência entre os valores dos hietogramas efetivos e hidrogramas de projetos resultantes, para o mesmo período de retorno estudado. Essas alterações são refletidas nos hidrogramas unitários e de projetos, Figuras 10 e 11 respectivamente, mostrando a redução do tempo de pico, podendo ser atribuído à medida que a área impermeável aumenta na bacia hidrográfica, sendo a vazão pouco elevada. 

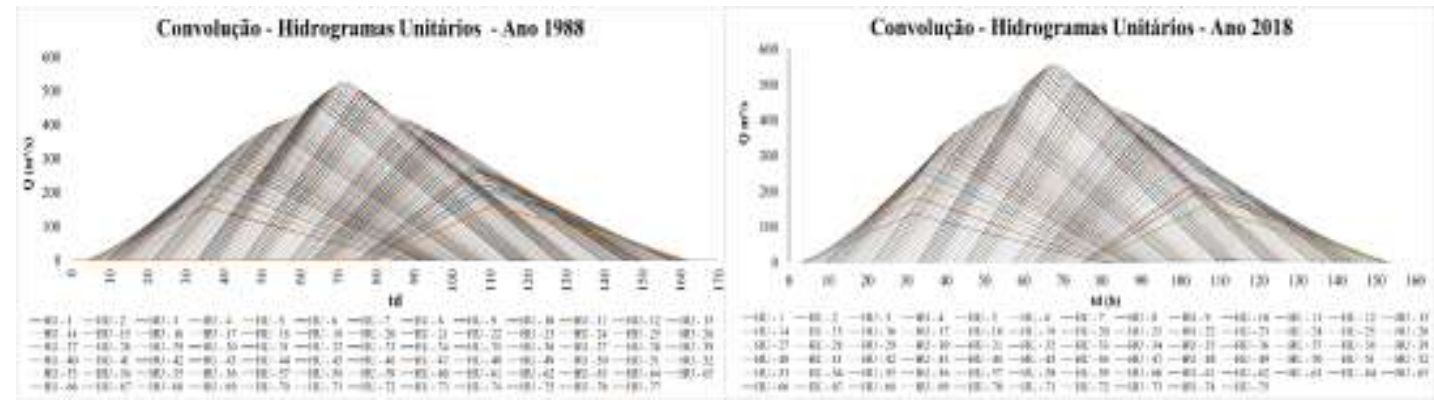

Figura 10 - Hidrogramas unitários pelo método de NRCS, para a bacia do igarapé Paragominas.
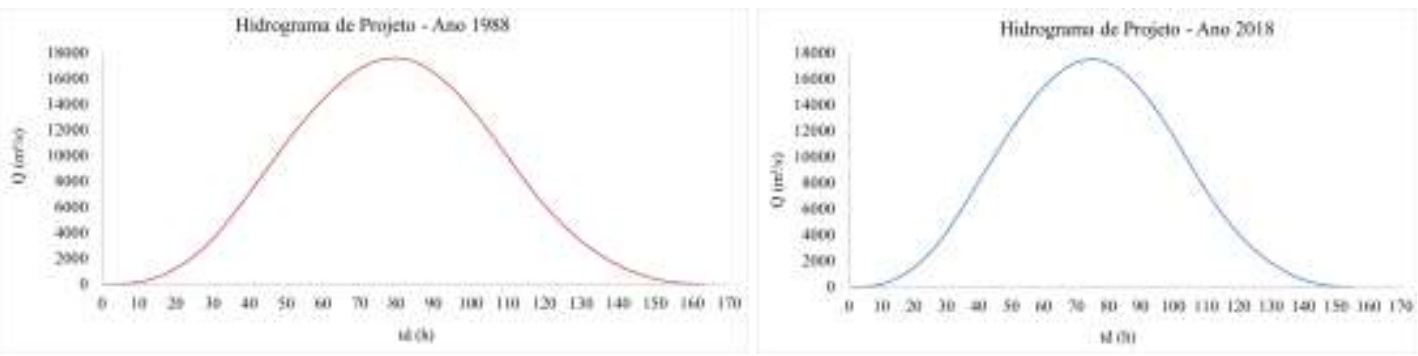

Figura 11 - Hidrogramas de projeto pelo método de NRCS, para a bacia do igarapé Paragominas.

A análise desses hidrogramas unitários relaciona ao efeito do escoamento superficial resultante da altura de chuva igual a $1 \mathrm{~mm}$. A junção das vazões dos hidrogramas unitários com as precipitações excedentes resultam nos hidrogramas de cheia dos cenários ambientais; a maior vazão encontrada nesses hidrogramas relacionados a cada período de retorno representam a vazão máxima obtida pelo método NRCS.

Fernandes et al. (2017) avaliaram a sensibilidade dos hidrogramas de cheias máximas obtidas pelo método do SCS (Soil Conservation Service) a variação do CN (Número da Curva) e ao tempo de concentração em uma microbacia urbana localizada no município de Juazeiro do Norte/CE, a partir da simuladção de 186 hidrogramas de vazões máximas a partir de seis cenários de uso e ocupação do solo e da variação do tempo de concentração com aplicação de sete equações para obtenção do tempo de concentração, e obtiveram como resultados a grande dependência na forma dos hidrogramas de vazões máximas obtidas pelo método do SCS ao valor do tempo de concentração e ao CN.

\section{CONCLUSÕES}

Existem diversas pesquisas desenvolvidas no âmbito análise de eventos extremos, contudo são poucas as que objetivam estimar o coeficiente de escoamento superficial, as curvas IDF, o hietograma e o hidrograma de projeto, pois são voltados mais para a verificação/análise dos efeitos desses eventos para a sociedade, especialmente na região amazônica.

O método NRCS, baseado nos valores de CN, mostrou-se versátil e fácil de se entender e aplicar, poir é um método eficaz no cálculo de vazões de escoamento superficial com confiabilidade e análise de multíplos cenários, fazendo uso de um conjunto de dados alcançado através do sensoriamento 
remoto e do geoprocessamento, possibilitando uma comparação temporal e sazonal.

O evento de chuva ocorrido na noite entre os dias 11 e 12 de abril de 2018 em Paragominas, onde em duas horas choveu uma altura pluviométrica de aproximadamente $130 \mathrm{~mm}$, caracteriza-se como um evento com elevado período de recorrência. Os dimensionamentos de projetos das 11 barragens na bacia provavelmente não alcaçaram a recorrência de 320 anos, tendo em vista que as barragens foram inundadas, ou seja, suas cotas de coroamento foram superadas pela altura de água gerada no escoamento superficial da bacia. Esta análise pode ser focada sob as alterações no coeficiente de escoamento superficial na bacia, ao longo do tempo, em virtude da evolução do uso e cobertura do solo, que podem não ter sido previstas no horizonte destes projetos hidráulicos.

Essa pesquisa evidenciou uma expansão das atividades agrícolas implicando em alterações da superfície e ocasionando desequilíbrio na fase terrestre do ciclo hidrológico. O aumento da precipitação efetiva e a diminuição do potencial de infiltração no solo provoca a diminuição das áreas de recarga e aumenta do escoamento superficial e, consequentemente, o valor do coeficiente de escoamento, resultando assim, em impactos as comunidades locais.

Observa-se a necessidade de repensar as lógicas de desenvolvimento seguidas, bem como planejar o crescimento da cidade, diante de seu uso e ocupação do solo, de forma que garanta maior capacidade de convivência com fenômenos climáticos extremos, cada vez mais frequentes.

\section{REFERÊNCIAS}

ALVES SOBRINHO, T.; PERTUSSATTI, C. A.; REBUCCI, L. C. S.; Oliveira, P. T. S.; Estimativa da erosividade local das chuvas, utilizando redes neurais artificiais. Revista Ambiente \& Água, v.6, p.246-254, 2011. Disponível em: <https://doi.org/10.4136/ambi-agua.197> . Acesso em 20 de julho de 2018.

ALVES, K. M. A.; CAVALCANTI, L. C. S.; NÓBREGA, R. S. Eventos extremos e risco de inundação: uma análise do comportamento evolutivo dos Distúrbios Ondulatórios de Leste em junho de 2010 sobre a bacia do rio Una Pernambuco. GeoTextos, vol. 9, n. 2, dez. 2013. K. Alves, L. Cavalcanti, R. Nóbrega. 173-189

ALVES, L. W. R. Diagnóstico agrícola do município de Paragominas-PA. Boletim de Pesquisa e Desenvolvimento 91. Belém, PA: Embrapa Amazônia Oriental, 2014. 26 p., 2014.

ANNIASINGAM, V.; BAGHIRATHAN, R.; SHAW, E.M. Rainfall depth-durationfrequency studies for Sri-Lanka. J. Hydrol., v. 37 (1978), pp. 223-239, .1978.

BAIRWA A. K.; KHOSA, R.; MAHESWARAN, R. Developing intensity duration frequency curves based on scaling theory using linear probability weighted moments: a case study from India. J. Hydrol., 542 (2016), pp. 850-859. Disponível em: <https://doi.org/10.1016/j.jhydrol.2016.09.056>. Acesso em 14 de julho de 2018. 
BASTOS, T. X.; PACHÊCO, N. A.; FIGUEIRÊdO, R. O.; SILVA, G. F. G. Características Agroclimáticas do Município de Paragominas. Características agroclimáticas 2005 FL-13646. Documentos 228, Embrapa, Nov. 2005.

BOLLMAN, H. A.; MARQUES, D. M. L. M. Critérios biológicos de qualidade das águas. Tucci, CEM \& Marques, DMM Avaliação e controle da drenagem urbana. ABRH, Porto Alegre, p. 125-175, 2001.

BORMA, L. De S.; NOBRE, C. A. Secas na Amazônia: causas e consequências. Oficina de Textos, 2013.

CANTÓN, $\mathrm{Y}$. et al. A review of runoff generation and soil erosion across scales in semiarid southeastern Spain. Journal of Arid Environments, Amsterdam, v. 75, n. 1, p. 1254-1261, 2011.

CARDONA, O. D. The need for rethinking the concepts of vulnerability and risk from a holistic perspective: a necessary review and criticism for effective risk management. In: BANKOFF, G.; FRERKS, G.; HILHORST, D. Mapping Vulnerability, Disasters, Development and People. London: Earthscan, 2004. p. 37-51, 2004..

CEDEC-SC, Resumo do desastre. $D$, disponível em http://www.desastre.sc.gov.br/ acessado em 13 de outubro de /03/2200918.

CHAMIZO, S.; CANTÓN, Y.; RODRÍGUEZ-CABALLERO, E.; DOMINGO, F.; ESCUDERO, A. Runoff at contrasting scales in a semiarid ecosystem: A complex balance between biological soil crust features and rainfall characteristics. Journal of Hydrology, v. 452-453, p. 130-138, 2012. Disponível em: < https://doi.org/10.1016/j.jhydrol.2012.05.045>. Acesso em: 09 de julho de 2018.

CHEN, C. Rainfall intensity-duration-frequency formulas. J. Hydraul. Eng. ASCE, v. 109 (1983), pp. 1603-1621, 1983.1. Disponível em: <DOI: 10.1061/(ASCE)0733-9429(1983)109:12(1603)>. Acesso em: 10 de julho de 2018

CLIMATE DATA. Clima de Paragominas. Disponível em: https://pt.climatedata.org/america-do-sul/brasil/para/paragominas-714961/. Acesso em 23 de março de 2020.

CORRÊA, J. B. L.; DIAS, H. C. T.; TONELLO, K. C.; CICCO, V.; SILVA, E.; S., L.; SATO, A. Y. Surface runoff of rainfall in anna experimental plantation of macaúba palm (Acrocomia aculeata) under differe iferentent forms of management. Revista Árvore. 2018, ; v. 42, n. (1),: e420104, 2018.. Disponível em: < http://www.scielo.br/pdf/rarv/v42n1/0100-6762-rarv-42-01e420104.pdf>. Acesso em: 16 de julho de 2018.

CUNHA, A. C. da et al. Evento Extremo de chuva-vazão na bacia hidrográfica do Rio Araguari, Amapá, Brasil. Revista Brasileira de Meteorologia, v. 29, n. SPE, p. 95-110, 2014.

DAVUDIRAD, A. A.; SADEGHI, S. H.; SADODDIN, A. The impact of development plans on hydrological changes in the Shazand Watershed, Iran. Land Degradation \& Development, v. 27, p. 1236- 1244, 2016. Disponível em: <https://doi.org/10.1002/Idr.2523>. Acesso em: 17 de julho de 2018. 
DE CASTRO, D. C. C.; RODRIGUES, R. S. S.; FERREIRA FILHO, D. F. Escoamento superficial na área convergente aos lagos Bolonha e Água Preta em Belém e Ananindeua, Pará. Research, Society and Development, v. 9, n. 3, 2019. DOI: http://dx.doi.org/10.33448/rsd-v9i3.2337.

DIEDERICHSEN, A.; GATTI, G.; NUMES, S.; PINTO, A. Diagnóstico dos fatores chave de sucesso para a restauração da paisagem florestal: Município de Paragominas e Estado do Pará Componente da Metodologia de Avaliação de Oportunidades de Restauração (ROAM) - Belém, PA: Imazon; Curitiba: Conserve Brasil, 2017.

DUARTE, C.C.; NÓBREGA, R. S.; COUTINHO, R. Q. Análise climatológica e dos eventos extremos de chuva no município do Ipojuca, Pernambuco. Revista de Geografia (UFPE) vV. 32, nNo. 2, 2015.

ELSEBAIE, I. H. Developing rainfall intensity-duration-frequency relationship for two regions in Saudi Arabia. J. King Saud Univ. Eng. Sci., v. 24, (2012), pp. 131-140, .2012. Disponível em: <doi:10.1016/j.jksues.2011.06.001>. Acesso em: 13 de julho de 2018.

FERNANDES, R. O.; COSTA, C. T. F.; STUDART, T. M. C. Análise de sensibilidade em hidrogramas de cheias máximas obtidos pelo método do scs em uma bacia urbana. Revista Águas Subterrâneas, (2017)v. 31, 1(n. 3):, p. 243-254, 2017. DOI: http://dx.doi.org/10.14295/ras.v31i3.28812.

FERREIRA FILHO, D. F.; RODRIGUES, R. S. S.; DA SILVA, M. de N. A.; FERNANDES, L. L.; CRISPIM, D. L. Aplicação de diferentes métodos de determinação de curvas de intensidade-duração-frequência no município de Belterra no estado do Pará, Brasil. Research, Society and Development, v. 9, n. 2, p. 1-26, 2019. DOI: http://dx.doi.org/10.33448/rsd-v9i2.2073.

G1. Disponivel em : <https://g1.globo.com/pa/para/noticia/prefeitura-deparagominas-confirma-rompimento-de-barragens-de-fazendas-na-regiao-aposenxurrada.ghtml>. 2018. Acesso em 18 de dezembro de 2019.

GARCEZ, L. N. Hidrologia, Editora Edgard Blücher Ltda, Editora da Universidade de São Paulo, São Paulo. 1967. 249 p.

GARCIA, J. R.; MIYAMOTO, B. C. B.; MAIA, A. G. Eventos extremos de precipitação: identificação e análise da bacia hidrográfica do Rio Jundiaí, São Paulo. Confins. Revue franco-brésilienne de géographie/Revista franco-brasilera de geografia, n. 37, 2018.

GENZ, F.; TUCCI, C. E. M. Infiltração em Superfícies Urbanas. Revista Brasileira de Engenharia. Caderno de Recursos Hídricos, v. 13, n. 1, p. 105- 124, jun. 1995.

GLOOR, M.; BRIENEN; R. J. W.; GALBRAITH, D.; FELDPAUSCH, T. R.; SCHÖNGART, J. GUYOT, J.-L.; ESPINOZA, J. C.; LLOYD, J.; PHILLIPS, O. L. Intensification of the Amazon hydrological cycle over the last two decades. Geophysical Research Letters, v. 40, p. 1729-1733, doi:10.1002/grl.50377, 2013.

GRIBBIN, J. E. Introdução à Hidráulica, Hidrologia e Gestão de Águas Pluviais. Tradução de Glauco Peres Damas. São Paulo: Cengage Learning, 2009. 
HAZBAVI, Z.; SADEGHI S. H. R. Potential effects of vinasse as a soil amendment to control runoff and soil loss. Soil, v.2, p.71-78, 2016. Disponível em: <https://doi.org/10.5194/soil-2-71-2016>. Acesso em: 11 de julho de 2018.

IBGE, Institudo Brasileiro de Geografia e Estatística. Censo, 2010. Disponível em: < http://www. censo2010. ibge. gov. br/>. Acesso em, v. 23, 2010.

IPCC - Intergovernmental Panel On Climate Change. 2014: Summary for policymakers. In: FIELD, C. B.; BARROS, V. R.; DOKKEN, D. J.; MACH, K. J.; MASTRANDREA, M. D.; BILIR, T. E.; CHATTERJEE, M.; EBI, K. L.; ESTRADA, Y. O.; GENOVA, R. C.; GIRMA, B.; KISSEL, E. S.; LEVY, A. N.; MACCRACKEN, S.; MASTRANDREA, P. R.; WHITE, L. L. (Eds.). Climate Change 2014: Impacts, Adaptation, and Vulnerability. Part A: Global and Sectoral Aspects. Contribution of Working Group II to the Fifth Assessment Report of the Intergovernmental Panel on Climate Change. Cambridge University Press, Cambridge, United Kingdom and New York, NY, USA. p. 1-32.

JOST, G. et al. A hillslope scale comparison of tree species influence on soil moisture dynamics and runoff processes during intense rainfall. Journal of Hydrology, Amsterdam, v. 420, n. 2, p. 112-124, 2012.

JUNQUEIRA JR., J.A.; DE MELLO, C.R.; ALVES, G.J. Eventos extremos de precipitação no Alto Rio Grande, MG: Análise probabilística. Revista Brasileira de Engenharia Agrícola e Ambiental-Agriambi, v. 19, n. 4, 2015.

KINNELL, P. I. A. Raindrop-impact-induced erosion processes and prediction: a review. Hydrol. Process., v. 19, (2005), pp. 2815-2844, 2015.. Disponível em: <https://doi.org/10.1002/hyp.5788>

KOUTSOYIANNIS, D.; KOZONIS, D.; MANETAS, A. A mathematical framework for studying rainfall intensity-duration-frequency relationships. J. Hydrol., v. 206, (1998), pp. 118-135, 1998.. Disponível em: <DOI: 10.1016/S00221694(98)00097-3>. Acesso em 11 de julho de 2018.

LEI No 597/2006. Institui o plano diretor de desenvolvimento urbano do município de Paragominas e dá outras providências. Disponível em: https://sogi8.sogi.com.br/Arquivo/Modulo113.MRID109/Registro31172/docume nto\%201\%20-\%20lei\%205972006\%20-\%20plano\%20diretor.pdf. Acesso em 23 de março de 2020.

MARCELLINI, S. S. Análise de critérios para a determinação das tormentas de projeto e sua influência nos hidrogramas em pequenas bacias hidrográficas. São Paulo: USP, 1994. 176p. Dissertação Mestrado.

MARENGO, J. A. BORMA, L. S., RODRIGUEZ, D. A., PINHO, P., SOARES, W. R., ALVES, L. M. ., 2013. Recent extremes of drought and flooding in Amazonia: vulnerabilities and human adaptation. American Journal of Climate Change, v. 2, p. 87-96, 2013..

MARTORANO, L. G.; MONTEIRO, D. C. A.; BRIENZA JUNIOR, S.; LISBOA, L. S.; ESPÍRITO SANTO, J. M.; ALMEIDA, R.F. Top-bioclimate conditions associated to natural occurrence of two Amazonian native tree species for sustainable reforestation in the State of Para, Brazil. In: VILLACAMPA, Y; BREBBIA, C. A. ECOSYSTEMS AND SUSTAINABLE DEVELOPMENT VIII. Ashurst Lodge: Wittpress, 2011. p.111-122, 2011.. 
MATOS, F. C.; TARGA, M. S.; BATISTA, G. T.; DIAS, N. W. Análise temporal da expansão urbana no entorno do Igarapé Tucunduba, Belém, PA, Brasil. Revista Biociências, v. 17, n. 1, p. 7-16, 2011.

MODRICKA, TM and GEORGAKAKOS KP. The character and causes of flash flood occurrence changes in mountainous small basins of Southern California under projected climatic change. Journal of Hydrology: Regional Studies, 2015, v. 3, p. : 312-336, 2015..

MONTEIRO, M. D. A.; COELHO, M. C. N.; BARBOSA, E. J. S. Atlas Sócio Ambiental: municípios de Tomé-Açú, Aurora do Pará, Ipixuna do Pará, Paragominas e Ulianópolis. Núcleo de Altos Estudos Amazônicos, ISBN, 987-85. 2009.

MONTENEGRO, A. A. A. et al. Impact of mulching on soil and water dynamics under intermittent simulated rainfall. Catena, Amsterdam, v. 109, n. 1, p. 139149, 2013.

MORAES, D.; COUTINHO, M. evento de precipitação intensa ocorrido nos dias 15 E 16 de abril de 2018 em Fortaleza-CE: Estudo de caso. Revista Brasileira de Climatologia, . Ano 15 - v. Vol. 25, - JUL/DEZ 2019.

MUÑOZ-ROBLES, C. et al. Soil hydrological and erosional responses in patches and inter-patches in vegetation states in semiarid Australia. Geoderma, Amsterdam, v. 160, n. 3, p. 524-534, 2011.

OLIVEIRA, P. T. S. DE; ALVES SOBRINHO, T.; RODRIGUES, D. B. B.; PANACHUKI, E. Erosion risk mapping applied to environmental zoning. Water Resources Management, v.25, p.1021-1036, 2011. Disponível em: <https://doi. org/10.1007/s11269-010-9739-0>. Acesso em 01 de Agosto de 2018.

OYEBANDE, L. Deriving rainfall intensity duration frequency relationships and estimates for regions with inadequate data. Hydrol. Sci. J., v. 27, (1982), pp. 353-367, 1982.. Disponível em: <DOI: 10.1080/02626668209491115>. Acesso em: 01 de Agosto de 2018.

PENG, T.; WANG, S. Effects of land use, land cover and rainfall regimes on the surface runoff and soil loss on karst slopes in southwest China. Catena, Amsterdam v. 90, n. 1, p. 53-62, 2012.

PINTO, A.; AMARAL, P.; SOUZA JR., C.; VERÍSSMO, A.; SALOMÃO, R.; GOMES, G.; BALIEIRO, C. Diagnóstico Socioeconômico e Florestal do Município de Paragominas. Relatório Técnico. Belém/PA: Instituto do Homem e Meio Ambiente da Amazônia - Imazon. 65 p. 2009.

POCCARD-CHAPUIS, R. Análise e considerações preliminares relativas ao episódio pluviométrico na cidade de Paragominas - PA, noite de 11 a 12 de abril de 2018. CIRAD, 2018.

REICHENBACH, P., CARDINALI, M., DE VITA, P and GUZZETTI, F. Regional hydrological thresholds for landslides and floods in the Tiber River Basin (central Italy). Environmental Geology, 1998, v. 35, n. (2, p. ):146 -159, $1998 .$.

RODRIGUES, R. S. S.; BITTENCOURT, G. M.; FERNANDES, L. L. Escoamento superficial em uma pequena bacia hidrográfica rural da Amazônia. Revista Brasileira de Cartografia, 2018, v. 70, n. (22, p. ):605 -- 628, 2018.. 
SADEGHI, S. H.; ZABIHI, M.; VAFAKHAH, M.; HAZBAVI, Z. Spatiotemporal mapping of rainfall erosivity index for different return periods in Iran. Natural Hazards, v. 87, p. 35-56, 2017. Disponível em: <https://doi. org/10.1007/s11069-017-2752-3>. Acesso em: 01 de agosto de 2018.

SANTOS, C.A.C.; MANZI, A.O. Eventos extremos de precipitação no estado do Ceará e suas relações com a temperatura dos Oceanos Tropicais. Revista Brasileira de Meteorologia, v. 26, n. 1, 2010.

SANTOS, S. R. Q.; SANSIGOLO, C. A.; NEVES, T. T. A. T.; CAMPOS, T. L. O. B.; SANTOS, A. P. P. Frequências dos eventos extremos de seca e chuva na Amazônia utilizando diferentes bancos de dados de precipitação. Revista Brasileira de Geografia Física. v.10, n.2, p. (2017) 468-478, 2017.

SCS - Soil Conservation Service. Hydrology. In: National engineering handbook. Washington: USDA, 1972. p.101-1023, $1972 .$.

SENA, J. P. O.; LUCENA, D. B.; RIBEIRO, G. N. Eventos extremos de precipitação no sertão paraibano: Variação espaço-temporal. Revista Verde de Agroecologia e Desenvolvimento Sustentável, v. V.12, n.No 4, p. 748-755, 2017. DOI: http://dx.doi.org/10.18378/rvads.v12i4.4938.

SERVIÇO GEOLÓGICO DO BRASIL - CPRM. Atlas Pluviométrico do Brasil: equações intensidade-duração-frequência. Município: Porto Alegre. Estação Pluviográfica: Porto Alegre, Códigos 03051011 (ANA) e 83967 (OMM). Porto Alegre: CPRM, 2015. 14 p.

SINGH, P. K.; BHUNYA, P. K.; MISHRA, S. K.; CHAUBE, U. C. A sediment graph model based on SCS-CN method. Journal of Hydrology, v. 349, p. 244-255, 2008. Disponível em: <https://doi.org/10.1016/j.jhydrol.2007.11.004>. Acesso em: 03 de agosto de 2018.

SOARES, M. R. G. de J. et al. Eficiência do método curve number de retenção de águas pluviais. Mercator (Fortaleza), v. 16, 2017.

SOUZA, L. A.; SOBREIRA, F. G. Bacia Hidrográfica do Ribeirão do Carmo: atributos morfométricos, equação de chuva intensa e tempo de concentração, e análise da suscetibilidade a inundação. Revista Brasileira de Cartografia, Rio de Janeiro, v. No 69, n. /7, p. 1355-1370, Jul/Ago/2017.

SOUZA, R. O. R. M.; SCARAMUSSA, P. H. M.; AMARAL, M. A. C. M.; PEREIRA NETO, J. A.; PANTOJA, A. V.; SADECK, L. W. R. Equações de chuvas intensas para o Estado do Pará. Revista Brasileira de Engenharia Agrícola e Ambiental, v. 16, n. 9, p. 999-1005, 2012.

TARGA, M. S. et al. Urbanização e escoamento superficial na bacia hidrográfica do Igarapé Tucunduba, Belém, PA, Brasil. Revista Ambiente \& Água, Taubaté, v.7, n.2, p. 120-142, 2012.

VALVERDE, María Cleofé. A interdependência entre vulnerabilidade climática e socioeconômica na região do abc paulista. Ambiente \& Sociedade. São Paulo v. $X X$, no 3, p. 39-60, jul.-set. 2017. Disponível em: < http://www.scielo.br/pdf/asoc/v20n3/pt_1809-4422-asoc-20-03-00039.pdf>.

Acesso em: 16 de julho de 2018 